\title{
The Study of the Development and Application Situation of Smart Finance
}

\author{
Junzhen Peng \\ Department of Accounting and Finance, Lancaster University, Lancaster, LA1 4YW, United Kingdom
}

\begin{abstract}
The great development of science and technology promotes the innovation and development of various industries and the continuous replacement drives many traditional industries to embark on the innovation road. Under this situation, smart finance stands out from the traditional finance industry and brings great influence on people's life. The paper introduces the concept, development situation and the application cases of the smart finance and displays some ideas about its future development.
\end{abstract}

Keywords: Traditional finance, smart finance, development situation, application cases, future development

\section{Introduction}

With the rapid development of internet technology, many new industries and innovation projects appear correspondingly, which can promote to provide better service for people. The traditional finance that can only provide deposit, loan and settlement services can only meet people's daily demands. In the past, people have to go to bank to complete related business, which will need long time and much effort and the process is very complicated. However, nowadays, people can complete basic transfer, deposit and other businesses easily by moving their figures while they are sitting at home. Undoubtedly, this change is caused by the rapid development of internet, and the active innovation and combination of internet and finance enterprises. It is until recent years that the concept of "smart finance" starts to appear in people's life and it furtherly optimizes the original services based on the old internet finance. It provides more convenient application condition for the public, provides safer protection for user's interest and benefits, can save labor cost for finance enterprises and promote the AI to come into people's life gradually. These benefits determine that the development momentum of smart finance cannot be underestimated and determine that the smart finance can break the operation models of traditional finance industry in very short time. The smart finance is greatly favored by the public. There is no doubt that smart finance will become the further study and development direction of future finance industry and will become the hot point in academic field and intelligent practice direction. It is also the finance development trend that I am interested in. Therefore, in the following part, I am going to start a series of introductions around smart finance so that you can have a further understanding of it.

\section{The Concept of Smart Finance}

Although smart finance has already influenced all aspects of our daily life, there must be someone who are not familiar with its concept yet. Thus, hereby I would like to give a brief introduction. Smart finance is a kind of new finance format that can change the service mode of traditional finance industry by relying on the internet of things and by applying the information technologies like big data, cloud computing and internet of things. It can change the customer experience, business procedure, organization structure, monitor and risk control mode. It can bring smoother monetary circulation, more convenient finance service, more personalized customer experience, more effective risk control and higher ability to serve the real economy (Song Zhixiu, 2020).

Same as traditional finance, smart finance does not change the essence of finance. The difference is that smart finance has the "smart" attribute and has the distinct characteristics of the high intelligence, popularization, precision, personalization, customization of finance products and services. In addition, the smart finance has great advantages in the aspects of improving finance efficiency, decreasing finance cost, optimizing finance service, preventing finance risk, improving the finance popularization ability. What's more, smart finance uses robots, systems or platforms to replace human service, which can reduce the labor investment in traditional finance. It drives the traditional finance to transform and upgrade its operation mode and to improve the smart attribute of its finance products and services so as to provide customers with more qualified and competitive service (Han Zhixiong, Feng Xuefen, Zhao Quan, 2018). In conclusion, in the competition between smart finance and traditional finance, smart finance wins mainly because of its smart attribute. 


\section{The Development Process and Current Situation of Smart Finance}

The development of smart finance is closely related with the development of cutting-edge information technology. The development and application of big data, intelligence and other information technology in related smart investment products and services in United States is leading the world. Based on the data information disclosed by Statista, the smart investment and management property in United States reached 224,820 million dollars in 2017 and will reach 509,555 million dollars in 2021. The compound annual growth rate is $29.3 \%$ (Han Zhixiong, Feng Xuefen, Zhao Quan, 2018).

China's smart finance is started later than other countries. Since the year 2016, GF Fund Merchant firstly launched the smart investment product called "Jizhi Finance Management" and then China Merchants Bank launched the "Mojie Smart Investment" product. Then, other banks and institutions began to launch a series of smart finance investment management products. In addition, during the enterprises' self-exploration process, China government launched the promotion policy very late. In The development plan of the new generation of artificial intelligence published in July, 2017, the State Council formally proposed to develop smart finance, to create innovative smart finance products and services and to develop new formats of smart finance. The transformation of China's traditional finance industry is started by letting the emerging technology of internet company to bring smart elements for the front-line finance business. The finance service branches also gradually adopted the smart service. In April, 2018, the first Chinese unmanned bank was established by Shanghai Branch of CCB. Only two smart robots worked in this bank and they could completely replace the bank tellers and service staff to complete the single or complicated counter business. Based on the biometric authentication, data collection technology, this smart technology can establish a highly smart service branch and can provide a completely self-service and smart platform for customers (Wang Linyue, 2020). While continuously combing the technology and finance together, the smart finance is also changing people's life imperceptibly.

\section{The Smart Finance Application Cases}

I believe that most people know Tencent. Tencent gradually develops from chat and game software to the software that combines online payment, finance investment management and chat functions together, which not only greatly shortens the distance among people but also changes the travelling and payment methods of most people. Some time ago, a rumor that the Central Bank of China will stop printing money and China will come into the cash-free era causes heated discussion before it is refuted. Although it is confirmed that this is only a rumor, I am inspired to think about whether the cash-free era will really come or not. Since the mobile payment is popularized, people in most cities and even in the whole country can make the daily payments required in daily life or daily travelling process and fewer and fewer people will choose to carry cash. Compared with cash payment, mobile phone payment is more convenient and people can avoid the trouble of loosing money. In addition, it can avoid the troubles of checking money and giving changes. In this way, people can complete transaction by a simple scanning. As the enterprises have gradually improved the technology and finance functions, the finance investment management can be conducted easily by moving our figures. The popular financial investment management products like Yu'E Bao, Ling Qian Tong and other products can ensure users to use money freely. Users can withdraw the money at any time if they need, which will not affect their interest. This benefit inspires many people who do not have financial investment management experience to try invest spare money and to experience the delight brought by financial investment and management.

Han Kaichuang, the vice president of Tencent Financial Research Institute, once mentioned "In future, the financial technology will develop toward the smart finance direction, and with the deepening of technology application in finance industry, the financial service will move forward along the smart direction. This shall be realized by accurately satisfying users' demands and experience demands and shall be realized based on the comprehensive application of various innovative technologies in the finance field ". The "project of smart life solution" proposed by Tencent is carried out based on the basic WeChat payment application. By far, it has covered millions of offline stores and over 30 industries, and it has comprehensively covered all daily life scenes. In addition, it has also realized the smart connection of "people-information-service-scene" (Sun Bing, 2019).

Of course, Alibaba, a company that advances at an equal pace with Tencent, is unwilling to be left behind. As early as 2013, Alibaba created Yu'E Bao which can be called as the pioneer product of internet finance industry and it brings great impact on traditional finance industry, especially on the current deposit business of the bank. In the year 2014, Ant Financial was formally established and it covered Alipay, Zhima Xinyong, MYbank, Zhima Credit, Ant Fortune and other digital modules. By the year 2018, the user of Ant Financial has reached 600 million and its asset value exceeds 150 billion dollars within only 4 years. By then, it has become the largest leading enterprise in global internet finance industry (Chen Yicheng, 2020). Then, the credit-based borrow and return function appears correspondingly. Now, the portable battery lease devices, shared bikes, umbrella lease devices and other convenient devices are very common. To use these devices, the citizens need to register their real name information and then the credit scoring will be carried out correspondingly. The users with high credit score can enjoy the deposit-free service and the users' borrow behavior will affect their credit score. It is the unconditional trust of enterprises on the Zhima Credit that promotes the birth of sharing industry, an industry that is convenient for our daily 
travelling. However, this can not only bring benefits but also has many disadvantages. Many lawbreakers will obtain extra benefit by helping some users to get cash from Ant Check Later platform. It is difficult to accurately judge the true repayment ability of these users that get cash from the platform by improper methods. In addition, the problems of capital loss caused by account theft is relatively serious for these users. Therefore, it can be seen that how to ensure the security of the users' account and how to try best to protect the asset security for users are the largest challenges for online finance app. Now, fingerprint unlocking technology, face recognition and other biotechnology appear one by one, which can improve the safety of online finance on certain degree. However, this cannot completely prevent loopholes. Thus, enterprises' technicians still need to make great and continuous efforts to solve this problem.

When mentioning the most cutting-edge and popular technologies of 2019, of course 5G internet cannot be ignored. From last year, China steps into $5 \mathrm{G}$ era and the application of $5 \mathrm{G}$ internet can undoubtedly bring positive influence on smart finance field. The characteristics of $5 \mathrm{G}$ internet can match with the massive data, real-time interaction and large business net characteristics of smart finance. Firstly, the peak speed of 5G technology can reach $10 \mathrm{Gbps}$ and the the time delay is as low as $1 \mathrm{~ms}$. It can connect with about 1 million sets of terminals per kilometers. Its large bandwidth and low time delay characteristics can greatly improve the service efficiency and speed up the financial transaction. Even in peak transaction time, customers do not need to be worried about the congestion caused by limited network capacity, which can improve customers' service experience. In addition, as 5G technology realizes the internet of everything, finance institutions can collect more comprehensive information and the financial data shows exponential growth. Meanwhile, the generation of mass data will promote the appearance of more reliable financial credit rating insinuations and the evaluation systems with broader dimension. It can improve the liquidity and transparency of market information, and can solve the high subjectivity, poor reliability and data fraud problems existing in current credit rating system (Wang Linyue, 2020). Although $5 \mathrm{G}$ technology has appeared for only a short time, it provides stabler development platform for smart finance market and its possible application fields can be furtherly expanded.

Compared with the newly launched 5G technology, blockchain technology is already a mature technology. Generally speaking, when people mention blockchain, they mean the blockchain technology. However, technically, blockchain and blockchain technology are two different concepts. Blockchain means the data record method that records data information by mathematics and technology methods, packs the data of a specified size to form a block, and then links the block into previous blocks to form an integrated data chain. However, blockchain technology means a kind of technology scheme that does not rely on any third party but relies on its own distribution nodes to realize data interaction, verification and storage.
Blockchain technology is originated from bitcoin. It is widely applied in credit certification, equity transaction and other fields owing to its own characteristics. It can not only realize the interaction of reliable information in an unreliable environment, but also has the innovative significance because of its technology decentralization, great convenience, security and transparency (Luo Huiyong, 2016). However, it also has safety problems. For example, once the user's private key for information interaction is lost, it is unable to reset the information. Based on its decentralization nature, the third party can not mediate problems and the forced operation can not be realized. Therefore, the right and interest redistribution can only be realized after the two parties have reached consensus. In addition, the transaction time delay and resource waste problems are also its obvious defects that are difficult to solve. While analyzing from the blockchain application aspect, it can be seen that it can mainly be applied in three major directions: information security service, public credit service and financial transaction service.

\section{Conclusion}

The convenience brought by smart finance has deeply influenced people's life. Therefore, people may be not familiar with its concept but must be very familiar with its application cases. Whiling bring people with great convenience, smart finance also has many problems. For instance, users' information may be leaked, or asset security may not be guaranteed or some possible new criminal methods may appear based on smart finance. Thus, when enjoying the convenience created by smart finance, enterprises shall emphasize the risk control, establish valid prevention methods for information network, prevent lawbreakers obtaining improper benefits by hacker behaviors so as to avoid users to suffer information theft or property loss.

China's finance industry is in a rapid development period and is continuously integrating with the whole world. The information management level of China finance industry's sub-industries and the different institutions of all sub-industries is every uneven. However, generally speaking, the information application of China's finance industry has reached the stage that data concentration, system integration and internet application can be realized and now it is striving forward to the service management stage. Under this situation, talent reserve has become the major task of this period. Thus, internally, we need to explore and cultivate the big data intelligent application experts that can master the technology and business knowledge. Externally, we need to expand the recruitment scope and introduce in the outstanding talents of this industry. In addition, enterprises shall actively seek for chances to cooperate with the research team of colleges and universities as well as financial science and technology enterprises and shall transfer the research results into the enterprises' scientific innovation in time. Meanwhile, sharing the big data information among finance enterprises 
is also a good method to promote the development of the whole industry.

The most important thing is that while establishing the correct smart finance development ideas and creating outstanding smart finance development environment, institutions shall make efforts to improve their competitiveness. Only by combing science and technology together with all kinds of finance industry chains can we establish the smart finance that can bring more convenience for people.

\section{REFERENCES}

[1] Han Zhixiong, Feng Xuefen, Zhao Quan. The analysis of the generation, development and prospect of smart finance. Hainan Finance, 2018, (08), 19-27.

[2] Song Zhixiu. The study on the smart finance establishment strategy adopted by China's commercial banks under the driven of big data. Contemporary Economics, 2020, (01),112-114.

[3] Wang Linyue. Research on the finance industry development. Modern Business Trade Industry, 2020,41(01), 17 .

[4] Chen Yicheng. The study on the comparative advantages of internet finance based on Ant Financial analysis. Modern Marketing (late edition), 2020, (01),35-36.

[5] Sun Bing. Han Kaichuang, vice president of Tencent Finance Research Institute: promote society and economy development by Tech for Social Good and smart finance. China Economic Weekly, 2019, (24),82-83

[6] Luo Huiyong. The work principles and application value of blockchain technology. Financial Perspectives Journal, 2016, (07), 33-37+76.

SMART FINANCE[J]. Business Today, 2016.

[7] Lehmann E E, Seitz N, Wirsching K. Smart finance for smart places to foster new venture creation[J]. Economia E Politica Industriale, 2017, 44(1):51-75.

[8] Lin Y R. Smart Finance and Cultivation Talent of Financial Information[J]. journal of shanghai finance university, 2011.

[9] Naijing H. Discussion of Shanghai Smart Finance Development $[\mathrm{J}]$. Journal of Shanghai Finance University, 2011.

[10] Manufacturing, Chemist. Encouraging growth in the pharmaceutical industry through smart finance[J].
Manufacturing Chemist Pharmaceutical Development Formulation Processing \& Outsourcing, 2017.

[11] Ling-Ge S, Jia-Yin C. Based on the Internet of Things and Cloud Computing Technologies to Develop Smart Finance[J]. Journal of Changchun Finance College, 2013.

[12] Huston S, Rahimzad R, Parsa A. 'Smart' finance for sustainable urban regeneration[J]. Cities, 2014.

[13] Kruglinski, Anthony. Tips for working 'smart' in finance[J]. Railway Age, 2002.

[14] Tseng K C. Behavioral Finance, Bounded Rationality, Neuro-Finance, and Traditional Finance[J]. Investment Management \& Financial Innovations, 2006, 3(4).

[15] Feng-Qi C. The Challenge of Internet Finance to Traditional Finance[J]. Finance Forum, 2015. 